\title{
THE MASTER PLANNING AND CONSTRUCTION PLAN OF FOREST CITIES BASED ON LOW CARBON EFFECT
}

\author{
SHAO, F. ${ }^{*}-$ XIE, X. D. \\ College of Architecture and Urban Planning, Qingdao University of Technology, Qingdao \\ 266033, China \\ *Corresponding author \\ e-mail: shaofengwid5545@126.com; phone: +86-180-3219-7955 \\ (Received $3^{\text {rd }}$ Apr 2019; accepted $17^{\text {th }}$ May 2019)
}

\begin{abstract}
With the growth of population and the rapid development of economic level, the emission of greenhouse gases increases greatly, and the form, degree and structure of resource utilization tend to be diversified. Based on the diversity of ecological environment, the utilization of resources shows the diversity of utilization functions. However, the unreasonable carbon emission leads to the decrease of the resource carrying capacity, and its prominent impact on the ecological environment is reflected in the population growth, the inharmonious development of the energy consumption and the urban greening construction. The results of this study show that economic development and forest city construction mutually promote each other. Expanding forest area and improving urban forest accessibility are the most direct effective way to achieve direct emission reduction and forest city target requirements. Based on the four major categories including basis, ecology, economy and industry, and culture covering 12 small indicators proposed by SWOT analysis, technical supports should be provided to the specific forest city planning and construction. This study provides a theoretical basis for the sustainable development of lowcarbon environment.
\end{abstract}

Keywords: low-carbon effect, resource carrying capacity, SWOT analysis, evaluation indicators, forest cities

\section{Introduction}

With the rapid development of urbanization and the sharp convergence of population in cities and towns, the urban industrialization represented by high energy, high consumption and high emissions has brought unprecedented opportunities to the development of cities. But at the same time its massive greenhouse gas emissions poses irreparable impact on the urban ecological environment and climate change (Huang et al., 2018; Gotovsky et al., 2018; Lodi et al., 2017; Marino et al., 2017; Oguzie et al., 2010; Han, 2011). A series of environmental problems resulting therefrom bring greater negative factors to the development of the cities (Wang and Watson, 2010). Currently, the greenhouse gas is an important contributor to global warming (Koo et al., 2014). High-energy carbon consumption is key to the production of greenhouse gases (Chuai et al., 2015). In view of the importance of a good ecological environment and a sustainable natural environment to urban development, many scholars have paid more and more important attention to the research on how to solve urban high emissions and realize the development of ecological balance (Duane et al., 2012). A great deal of research on ecocities focus on how to realize the development mode of low-carbon circular economy and the application method of low-carbon effect to the sustainable development of ecological environment (Hosseini and Rezaei, 2013; Scully-Russ, 2012). The theory of low-carbon city put forward is suitable for the urban development in China at present, so the theory of urban planning and construction based on low-carbon effect is of great significance. 
Population, resources, environment and development constitute the sub-system of regional economic development, which is the main problem that affects the economic development of a region. To solve this problem from the root, a large number of scholars and urban development practice have given the direction - low-carbon circular economy development model, the low-carbon model of resources development and utilization is designed to promote regional economic development, and a region's carbon consumption and environmental capacity is proportional (Chen, 2012). However, high energy carbon emissions are bound to cause damage to ecosystems (Liu et al., 2017; Yang and Kong, 2012). If human beings want to survive and develop, they must consume resources. If they want to develop sustainably, they must develop and utilize resources according to local conditions on the basis of not destroying the ecological environment. The carrying capacity of resources in a region is limited. Under the action of ecological drive, the carrying capacity of regional resources is gradually decreasing. At present, the comprehensive evaluation indicator of resource utilization efficiency and economic development is ecological footprint. The study of ecological footprint is based on the complex system of "ecology-economy-sustainability". The forest city is an effective way to alleviate the warming of atmospheric environment and solve the greenhouse gas emission. The environmental capacity and forest greening rate of a region are the key indexes to measure the construction of forest cities. Based on the action of low-carbon effect, this study discusses the master planning and construction plan of forest cities, establishes the urban economic development model of low-carbon effect, and realizes the sustainable development of urban regional economy.

\section{Materials and methods}

The ecological sensitivity of forest cities is the key index to judge the carrying capacity of forest cities based on the principle of low-carbon consumption, and the ecological environment state is evaluated according to the concept and method of ecology and sustainable development to balance the specific population. The amount of green resources that people need to offset the hazardous substances released for the development of production and consumption of human is the basis for planning the plot ratio of forest cities (Mcintosh et al., 2015; Burrows and Appold, 2015). The calculation of the ecological rate is as shown in Equation 1, and the evaluation index is shown in Table 1:

$$
\mathrm{EF}=\mathrm{N} \times \mathrm{ef}=\mathrm{N} \sum_{\mathrm{i}=1}^{\mathrm{n}}(\mathrm{ai})=\mathrm{N} \sum_{\mathrm{i}=1}^{\mathrm{n}}\left(\mathrm{C}_{\mathrm{i}} / P_{i}\right)(i=1.2 .3 \ldots n)
$$

$\mathrm{EF}$ is the total index of ecological sensitivity; $\mathrm{N}$ is the number of urban carbon consumption items; ef is the equivalent value of carbon consumption per capita in the city; $\mathrm{N}$ is the population; $i$ is the type and attribute of consumer goods; ai is the biological production area occupied by each person of the i-th substance; $C_{i}$ is the average oxygen released by the $\mathrm{i}$-th greening species; $P_{i}$ is the average production capacity of the i-th substance.

Ecological environmental carrying capacity refers to the ratio of released greenhouse waste to waste absorbed by photosynthesis of green plants. The value of the carrying capacity required for forest city development is expressed as (Schebitz et al., 2014): 


$$
\mathrm{FR}=(\mathrm{PW}+\mathrm{DW}) \times(1-\delta)
$$

where PW represent the carbon value of the production emission; DW indicates the scale of forest greening; $\delta$ represents the carbon consumption rate.

Table 1. Evaluation factors and their classification of the ecological sensitivity

\begin{tabular}{c|c|c|c|c|c}
\hline Ecological factors & Insensitivity & $\begin{array}{c}\text { Slight } \\
\text { sensitive }\end{array}$ & $\begin{array}{c}\text { Moderately } \\
\text { sensitive }\end{array}$ & $\begin{array}{c}\text { Highly } \\
\text { sensitive }\end{array}$ & $\begin{array}{c}\text { Extremely } \\
\text { sensitive }\end{array}$ \\
\hline Vegetation & $<0.33$ & $0.33 \sim 0.52$ & $0.53 \sim 0.64$ & $0.65 \sim 0.72$ & $\geq 0.73$ \\
Slope & $<4$ & $4-9.2$ & $9.3-14.6$ & $14.7 \sim 31.2$ & $\geq 33$ \\
Altitude & $<145$ & $146-287$ & $288 \sim 476$ & $478 \sim 792$ & $\geq 793$ \\
Hierarchical assignment & 1 & 3 & 5 & 7 & 9 \\
\hline
\end{tabular}

\section{Results}

\section{SWOT analysis of establishing low-carbon effect forest cities}

The SWOT analysis will examine the strengths, weaknesses, opportunities, and challenges of the subjects studied. Through detailed investigation and analysis, the influencing factors are sequenced according to the importance and the correlation analysis is arranged in matrix mode. Then, the relationship among the various factors is analyzed with system analysis under the principle of mutual matching. In order to construct a forest city with low carbon effect, SWOT analysis should be carried out on the construction of the city according to the results of statistical investigation, and the construction strategy of SWOT analysis strategy for forest city construction is shown in Table 2.

Table 2. The construction of national forest SWOT strategy analysis matrix

\begin{tabular}{|c|c|c|c|c|c|}
\hline \multirow{3}{*}{$\begin{array}{c}\text { Classification } \\
\\
\text { Internal } \\
\text { conditions }\end{array}$} & \multirow{2}{*}{$\begin{array}{l}\text { Category } \\
\text { Strength }\end{array}$} & \multicolumn{4}{|c|}{ Analysis process } \\
\hline & & $\begin{array}{c}\text { Government } \\
\text { Attention }\end{array}$ & $\begin{array}{l}\text { Abundant } \\
\text { resources }\end{array}$ & $\begin{array}{c}\text { Urban priority } \\
\text { development zone }\end{array}$ & $\begin{array}{l}\text { Experience } \\
\text { and reference }\end{array}$ \\
\hline & Weakness & $\begin{array}{l}\text { Potential hazards } \\
\text { of soil and water } \\
\text { resources }\end{array}$ & $\begin{array}{c}\text { Forestry } \\
\text { development } \\
\text { guarantee }\end{array}$ & $\begin{array}{l}\text { Land used for } \\
\text { building }\end{array}$ & \\
\hline \multirow{2}{*}{$\begin{array}{l}\text { External } \\
\text { conditions }\end{array}$} & Opportunities & Opportunity & Strategy & Policy & Upsurge \\
\hline & \begin{tabular}{|l|} 
Threats \\
\end{tabular} & Development & Compete & Ecological function & Capital \\
\hline
\end{tabular}

In accordance with the analysis model of Table 1, with reference to the data of Yearbook of the National Bureau of Statistics in 2018, the low-carbon construction effect and the total investment ratio of forest construction of major green forest cities are analyzed according to the ecological sensitivity and carrying capacity calculation scheme, providing practical support for the feasibility analysis, with the results shown in Figure 1.

Figure 1 shows that the SWOT analysis indexes analyzed in this study are positively correlated with the construction planning effect of the forest cities. In light of the fact that the primary task of the master planning of forest cities based on the low-carbon effect is to carry out the SWOT analysis on a statistical basis, and according to the 
above analysis plan and the examples of the construction of individual cities, it is confirmed that the construction of forest-oriented cities should be analyzed from the following three aspects. First, the SWOT analysis on the construction of the city as a forest city shall be thoroughly carried out to clearly recognize that the city in the construction process needs what experience data and absorb what ways and methods for improvement. Second, we should formulate a strategy for the development of lowcarbon economy for modernization, so that the economic development of cities should be coordinated with the construction of ecological environment and the construction of national forests. Third, we should actively respond to the challenges brought by the acceleration of the green urbanization process, analyze the national policies and local environmental characteristics, dare to expose the problems, turn the disadvantages into advantages for the development, and strengthen the situation and determination of realizing the low-carbon forest cities. From the above three aspects, the changing trend of the greening rate of the main greening cities in different years is shown in Figure 2.

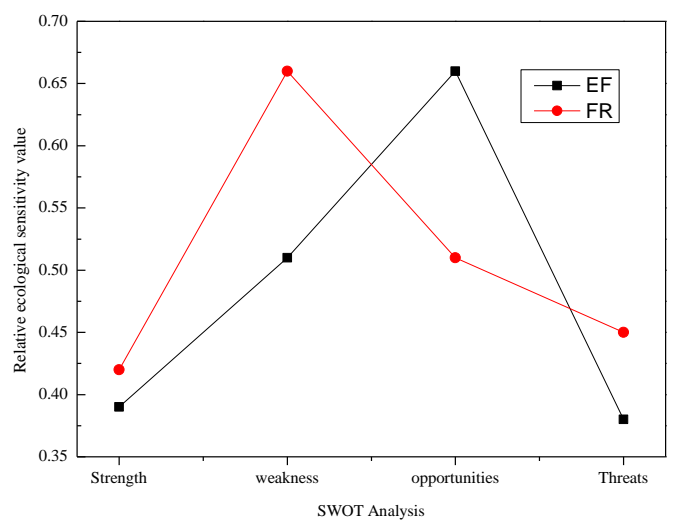

Figure 1. Statistical analysis of different evaluation indicators based on SWOT

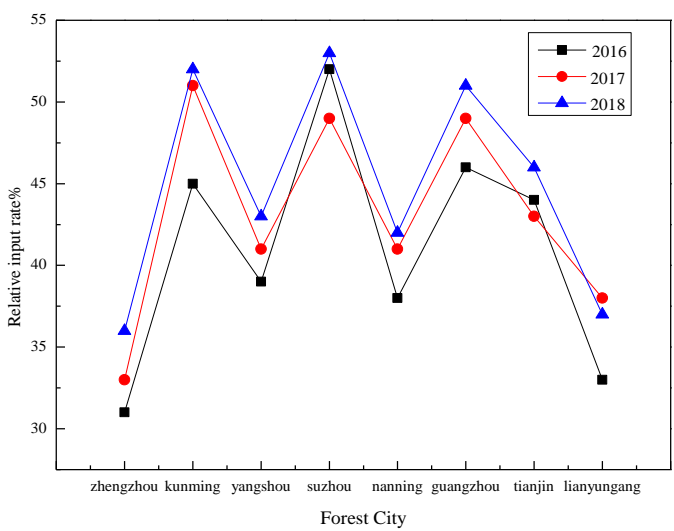

Figure 2. Statistical value of greening rate of green city in different years

\section{Construction of forest city evaluation indexes based on low-carbon requirements}

After the SWOT analysis on the construction of low-carbon forest cities, it is necessary to establish quantifiable evaluation indexes to measure the specific targets and strategies of forest urban planning and construction. In this study, forest city 
sensitivity and low-carbon effect bearing capacity are used to measure the result of the comprehensive action of human and natural environment, and the balance of ecological environment causes the changes in regional material flow, energy flow and information flow, so as to construct the evaluation indexes and provide technical support for the construction of forest cities with low-carbon effect as the target. According to the four factors of basic index, ecological index, economic and industrial index and cultural index, this study evaluates the order and feasibility criterion of construction index. Refer to Table 3 for comprehensive evaluation index and its reference value.

Table 3. Establishing evaluation index of green forest city

\begin{tabular}{|c|c|c|c|}
\hline Index system & Evaluation content & Quantitative indicators & Low carbon significance \\
\hline \multirow{5}{*}{ Basic index } & Forest coverage & $\geq 35 \%$ & \multirow{2}{*}{ Carbon absorption } \\
\hline & Urban green coverage rate & $\geq 40 \%$ & \\
\hline & Per capita park green space & More than $11 \mathrm{~m}^{2}$ & \multirow{3}{*}{$\begin{array}{l}\text { Fixed carbon emission } \\
\text { reduction }\end{array}$} \\
\hline & $\begin{array}{c}\text { Greening of important } \\
\text { water sources }\end{array}$ & $\geq 55 \%$ & \\
\hline & Road greening & $\geq 70 \%$ & \\
\hline \multirow{3}{*}{$\begin{array}{l}\text { Ecological } \\
\text { indicators }\end{array}$} & Suburban forest naturalness & Naturality below 0.5 & \multirow{3}{*}{ Improving forest quality } \\
\hline & \begin{tabular}{|c|} 
Bio-diversity \\
\end{tabular} & Species diversity & \\
\hline & Forest soil protection & Reducing soil and water loss & \\
\hline \multirow{4}{*}{$\begin{array}{l}\text { Economic and } \\
\text { industrial } \\
\text { indicators }\end{array}$} & $\begin{array}{c}\text { Forest tending and forest } \\
\text { management }\end{array}$ & Close to nature & \multirow{4}{*}{$\begin{array}{l}\text { Developing low carbon } \\
\text { economy }\end{array}$} \\
\hline & Ecotourism & Ecotourism construction & \\
\hline & Forest production base & Forest related income & \\
\hline & Forest nursery & Self-sufficiency rate $\geq 70 \%$ & \\
\hline \multirow{2}{*}{$\begin{array}{l}\text { Cultural } \\
\text { indicators }\end{array}$} & Popular science sites & $\begin{array}{c}\text { Number of popular science } \\
\text { places }\end{array}$ & \multirow{2}{*}{$\begin{array}{l}\text { Improving forest carbon } \\
\text { sequestration }\end{array}$} \\
\hline & Voluntary tree planting & $\begin{array}{c}\text { Compulsory tree planting } \\
\text { rate for all }\end{array}$ & \\
\hline
\end{tabular}

Table 3 summarizes and analyzes the master planning and evaluation indexes for the construction of low-carbon cities. To build low-carbon forest cities, it is first to combine the index requirements of national forest cities and to compare the current situation of the city with the actual data according to a large number of investigations. In accordance with the evaluation result, the corresponding strategies are adopted. The overall construction idea of forest cities at the present stage is to increase the forest coverage rate, the green area, the green belt area, and the green rate, adopt the appropriate forest seedling cultivation method and expand popular science places to improve the forest city construction planning based on the low-carbon effect.

\section{Discussion}

\section{Sustainable low carbon forest city planning}

The evaluation index of constructing low-carbon forest cities provides the basis and direction for the master planning of constructing low-carbon forest cities. How to realize the sustainable, reduced and economical low-carbon city construction needs to 
have clear planning idea and construction outline in the planning. Based on the literature review and the results of forest city construction, this study puts forward the process and method of low-carbon city construction. The definition of low-carbon cities mainly includes low-carbon city, low-carbon city life, low-carbon city economy, lowcarbon urban transportation and low-carbon urban culture. The low-carbon urban forests include low-carbon urban forest construction and urban forest conservation. The low carbon city life explores the code of conduct for low-carbon cities. The low-carbon urban transportation only considers the urban overrunning road. The low-carbon city culture focuses on the publicity and education of the concepts related to the low carbon and urban forests and forest cities. See Figure 3 for the constituent elements of the lowcarbon forest city construction.

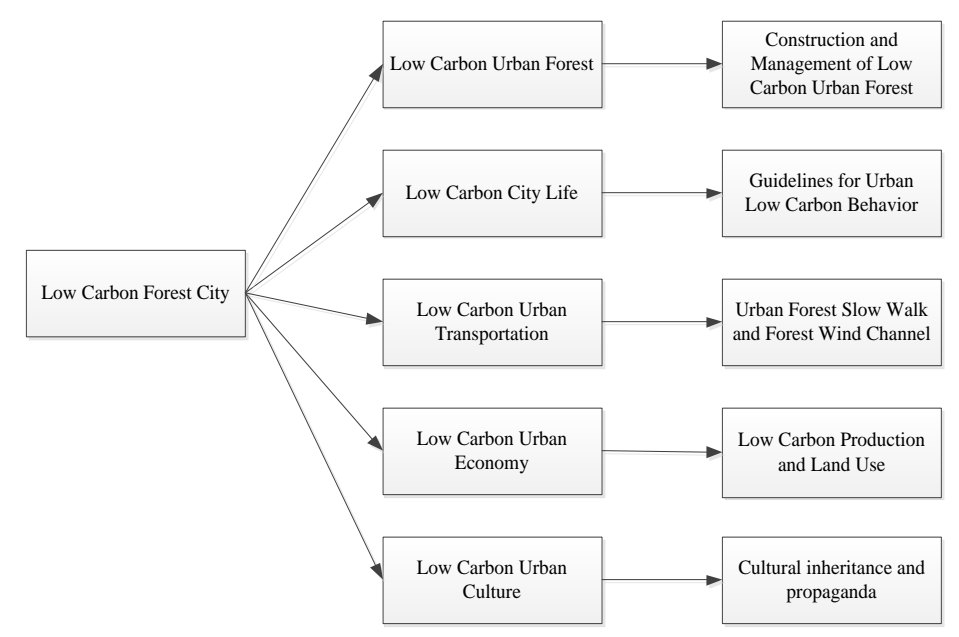

Figure 3. Low-carbon forest city form the element-level analysis

\section{Feasibility method of forest city construction with low-carbon effect}

In order to control the steady state of forest ecological carrying capacity, it is necessary to control the relationship among population scale, economic development and resource carrying capacity. Figure 4 is a two-way optimization model of forest environmental carrying capacity and population scale. It can be seen that with the continuous improvement of the economic level, the population scale will correspondingly increase, and when the population scale increases to a certain amount, the economic level will show relatively rapid growth. Carbon emissions are proportional to population scale. People's production and living activities will result in greater carbon emissions. That is to say, the moderate population scale related to living standards will increase with the increase of carbon emissions and the improvement of economic level. Therefore, the development is on the rise or in the developed cities, the analysis of the population structure and industrial structure can show that the urban construction based on low-carbon effect is imminent and suitable for carbon emission evaluation so as to put forward the feasibility of the construction planning plan purposefully.

Based on the feasibility plan for urban forest construction, it is necessary to make clear the main contents of the low carbon for forest cities and deduce the design scheme that satisfies the evaluation method through function analysis. The main functions of the scheme are as follows: first, direct emission reduction; second, indirect emission 
reduction; third, increase in the ecological capacity. On the one hand, urban forest can directly reduce the carbon dioxide content by absorbing carbon dioxide, which is a direct effective way to realize low-carbon content of cities. On the other hand, the rational distribution of urban forest can completely change the pattern of urban land use, make the urban green land more reasonable, and reduce the concentration distribution of urban carbon emissions to a certain extent. Secondly, the vertical gas exchange is increased by the transpiration of the forests, so the heat island effect is alleviated, and the gas emission and accumulation of the greenhouse can be effectively reduced. Therefore, the direct low-carbon measures of low-carbon forest cities are to build urban forests vigorously. Its main function is shown in Figure 5.

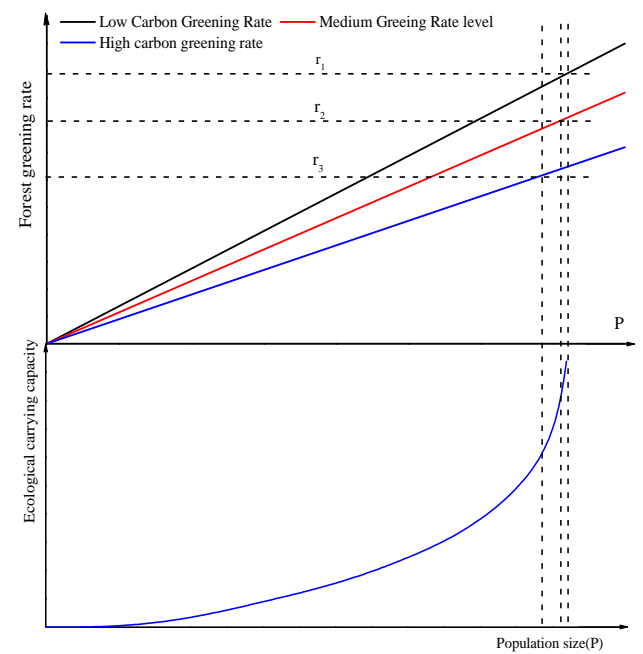

Figure 4. Two-way optimization model of ecological equilibrium capacity and population size

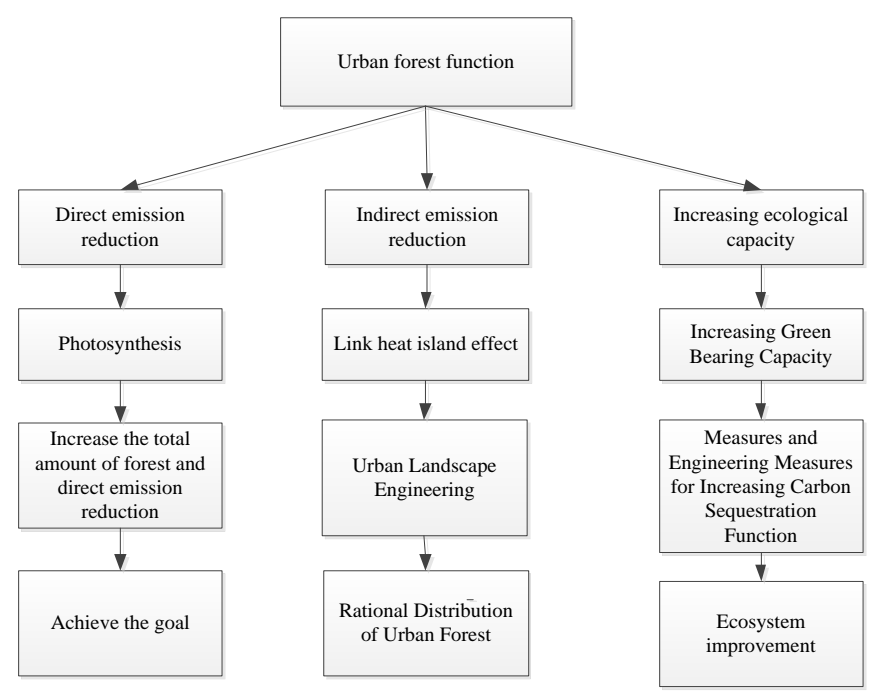

Figure 5. Low-carbon effect analysis diagram of the urban forest

Through the judgment of the evaluation indicators for the construction of forest cities with low-carbon effect and the understanding of the feasibility construction steps of the construction plan and their significance, the conceptual and leading guidance is 
provided for the master planning, but the overall construction plan of forest cities is based on the statistical mathematics, probability mathematics, analysis and checking computations. Therefore, in order to have a clearer working step for the overall construction plan, it is necessary to clarify the thought of study on the accessibility of urban forest construction. By referring to Figure 6 and through accessibility analysis, it is possible to identify the weak points of greening construction and the points to be strengthened, so as to carry out targeted and planned implementation of block division units for forest city construction.

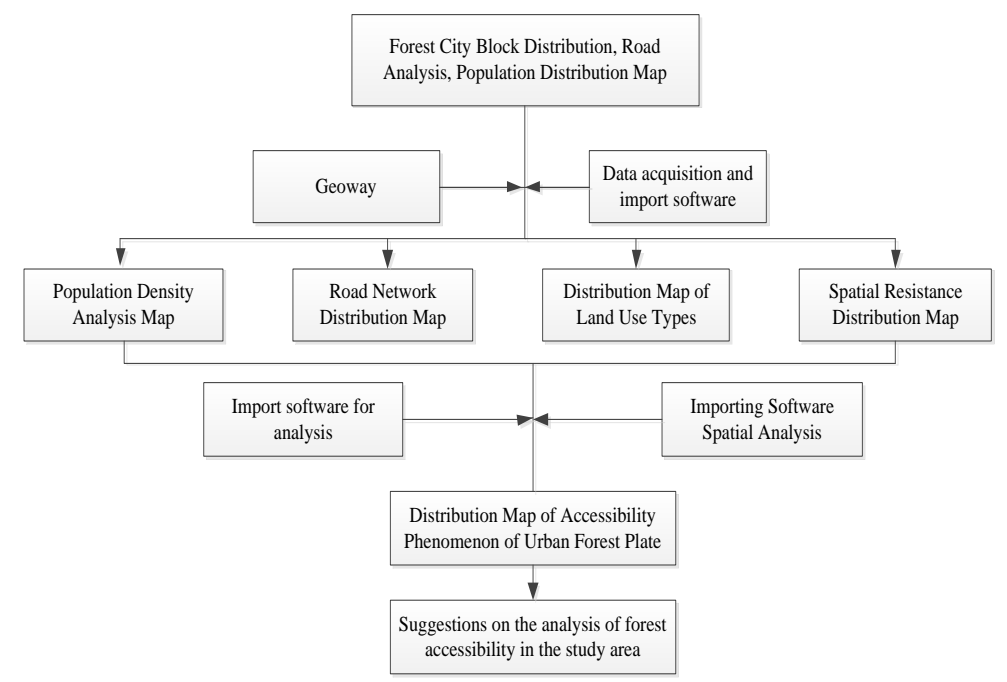

Figure 6. The research route of achieving standards in forest cities

\section{Conclusions}

Based on the principle of low-carbon effect, this study makes qualitative and quantitative analysis on the master planning and construction steps of forest cities, and thus provides the basis for sustainable and low-carbon forest city construction. The concrete conclusions are as follows:

(1) The driving factors of the change in the low-carbon environmental carrying capacity include natural factors and human factors, the growth of population and the construction of urbanization industry can promote the construction of forest cities to a certain extent, expanding the forest area and improving urban forest accessibility is the most direct and effective way to achieve the direct emission reduction and forest city target;

(2) This study introduces SWOT analysis and puts forward the evaluation indexes of forest const ruction covering 4 major categories and 12 small categories, providing data support for the hypothesis on the master planning;

(3) The construction of low-carbon forest cities has the sustainable development significance to the development of cities. The construction of low-carbon forest city in the future is the supporting construction project of industrialization development. The study provides the qualitative analysis index for the overall construction and planning of forest cities and also offers the basis and scheme for the basic research on the construction of forest cities. 


\section{REFERENCES}

[1] Burrows, C. R., Appold, M. S. (2015): Hydrology of the forest city basin, mid-continent, USA: implications for $\mathrm{CO}_{2}$ sequestration in the St. Peter Sandstone. - Environmental Earth Sciences 73(4): 1409-1425.

[2] Chen, H. (2012): Establishment of national forest city based on the construction of ecological civilization in china. - Fish Physiology \& Biochemistry 38(4): 1099-106.

[3] Chuai, X., Huang, X., Wang, W., Zhao, R., Zhang, M., Wu, C. (2015): Land use, total carbon emissions change and low carbon land management in coastal Jiangsu, China. Journal of Cleaner Production 103: 77-86.

[4] Duane, B., Hyland, J., Rowan, J. S., Archibald, B. (2012): Taking a bite out of Scotland's dental carbon emissions in the transition to a low carbon future. - Public Health 126(9): 770-777.

[5] Gotovsky, M., Gotovsky, A., Mikhailov, V., Kolpakov, S., Lychakov, V., Sukhorukov, Y. (2018): Formic acid cycle as partial alternative to Allam cycle less expensive and simpler. - Tecnica Italiana - Italian Journal of Engineering Science 61+1(2): 49-54.

[6] Han, Y., Shi, J., Xu, L., Cao, W. Q., Dong, H. (2011): Tic precipitation induced effect on microstructure and mechanical properties in low carbon medium manganese steel. Materials Science \& Engineering A 530: 643-651.

[7] Hosseini, S. M., Rezaei, A. (2013): Developing an information system for sustainable natural resource management in Alborz watershed, northern Iran. - Systemic Practice and Action Research 26(2): 131-152.

[8] Huang, K., Yang, X., Lu, Y., Mi, C. C., Kondlapudi, P. (2018): Ecological driving system for connected/automated vehicles using a two-stage control hierarchy. - IEEE Transactions on Intelligent Transportation Systems 19(7): 2373-2384.

[9] Koo, C., Kim, H., Hong, T. (2014): Framework for the analysis of the low-carbon scenario 2020 to achieve the national carbon emissions reduction target: focused on educational facilities. - Energy Policy 73: 356-367.

[10] Liu, Y., Tian, Y., Chen, M. (2017): Research on the prediction of carbon emission based on the chaos theory and neural network. - International Journal Bioautomation 21(S4): 339-348.

[11] Lodi, C., Malaguti, V., Contini, F. M., Sala, L., Muscio, A., Tartarini, P. (2017): University energy planning for reducing energy consumption and GHG emissions: the case study of a university campus in Italy. - International Journal of Heat and Technology 35(S1): S27-S32.

[12] Marino, C., Nucara, A., Nucera, G., Pietrafesa, M. (2017): Economic, energetic and environmental analysis of the waste management system of Reggio Calabria. International Journal of Heat and Technology 35(S1): S108-S116.

[13] Mcintosh, J., Martini, A., Petsch, S., Huang, R., Nüsslein, K. (2015): Biogeochemistry of the forest city basin coalbed methane play. - International Journal of Coal Geology 76(1): 111-118.

[14] Oguzie, E. E., Enenebeaku, C. K., Akalezi, C. O., Okoro, S. C., Ayuk, A. A., Ejike, E. N. (2010): Adsorption and corrosion-inhibiting effect of Dacryodis edulis extract on lowcarbon-steel corrosion in acidic media. - Journal of Colloid and Interface Science 349(1): 283-292.

[15] Schebitz, N., Brockmann, M., Schie, L. C., Kuck, D., Staubach, M., Fricke, N. (2014): Information modalities and timing of ecological driving support advices. - IET Intelligent Transport Systems 8(6): 534-542.

[16] Scully-Russ, E. (2012): Human resource development and sustainability: beyond sustainable organizations. - Human Resource Development International 15(4): 399-415.

[17] Wang, T., Watson, J. (2010): Scenario analysis of China's emissions pathways in the 21st century for low carbon transition. - Energy Policy 38(7): 3537-3546. 
[18] Yang, S., Kong, D. (2012): Expansion of construction land and its effect on forest based on road network character: a case study of Shenzhen city. - Ecology \& Environmental Sciences 21(2): 286-292. 